\title{
Misuse of Lambda $(\lambda)$ in NRCS-CN Model
}

\author{
Wen Jia Tan ${ }^{1 *}$, Jen Feng Khor ${ }^{1}$, Lloyd Ling $^{1}$ and Yuk Feng Huang ${ }^{1}$ \\ ${ }^{1}$ Lee Kong Chian Faculty of Engineering and Science, Universiti Tunku Abdul Rahman, 41600 \\ Kajang Selangor, Malaysia
}

\begin{abstract}
Since 1954, the Soil Conservation Curve Number (SCS-CN) method is widely applied in hydrological field to predict the direct runoff resulting from event rainfall. Originally, the lambda value was fixed at 0.2. However, based on recent studies, the simplied SCS-CN method was unable to predict a consistent and accurate runoff amount. Most of the research studies in various countries claimed that lambda value was a variable and most likely should be less than 0.2 . Most of the researchers applied either mean or median $\lambda$ value directly without checking the statistics. Misuse of lambda value in SCS-CN model will lead to inconsistent runoff estimation. Moreover, although $\lambda$ value can be determined, the equivalent $C N_{0.2}$ cannot be found. Some of research studies or even Hydrology Textbook substitute $S_{\lambda}$ directly into $C N$ equation and lead to wrong $C N$ calculation. In this study, the statistical significant $\lambda$ value and regional specific $S$ correlation are developed under the guide of non-parametric inferential statistics. by using bootstrapping, Bias corrected and accelerated (BCa) technique with 2000 samples
\end{abstract}

\section{Introduction}

Quantifying runoff from a storm event is a vital part of rainfall-runoff model development. The soil conservation curve number (SCS-CN) method is a popular elementary empirical model that is widely used in many countries to estimate surface runoff for a given rainfallrunoff and it is still in used as a lumped model today. SCS-CN model is one of the rainfallrunoff models with the least input parameter. This SCS-CN model is documented in the National Engineering Handbook, Sect. 4: Hydrology (NEH-4) [41-42, 45]. The initial abstraction ratio $(\lambda)$ is an important parameter in SCS-CN method that is largely influenced by climate condition of the watershed [33]. Traditionally, $\lambda$ is fixed at 0.2 [41-42, 45]. However, the lambda value equivalent to 0.2 and used as a constant parameter in SCS-CN model is the most ambiguous assumption. This assumption did not have scientific proof and had led to inconclusive opinions about lambda value from other researchers $[1-2,7-8,12,16$, $39,47,51-52]$. Based on few recent studies which had stated that the $\lambda=0.2$ was unusually

\footnotetext{
* Corresponding author: tanwenjia0104@,1utar.my
} 
high and it had the tendency of overestimating the surface runoff whereas the lambda value lower than 0.2 was better fit the observed rainfall-runoff data [2, 7-8, 14, 18, 30, 39-40, 48]. Recent researches which were studied in 2000 [16] and 2015 [27] had claimed that the best fit lambda value should be 0.111 and 0.112 respectively instead of 0.2 based on the 112 data in United State of America (USA) plotted on the log-log scale graph available in National Engineering Handbook, section 4 (NEH4) Chapter 10 Figure 10.2 [45]. As a result, the lambda value requires refinement for regional watershed [1].

Most of the research studies about SCS-CN model in various countries [4-5, 37, 41-42, $43,45]$ had claimed that the lambda value varies in the range of $(0,0.3)$. Under the low rainfall amount and semi-arid watersheds condition, Yuan et al (2014) [51] found out $\lambda$ value varies between 0.01 and 0.53 for different Walnut Gulch (USA) catchments in southeastern Arizona. In India, the lambda value for black clay is directly classified as 0.1 whereas the rest of soil is using $\lambda=0.3$. There is still no scientific proof on the classification of lambda value used in India until today $[15,42]$. However, the selection between mean and median became a universal dilemma in hydrological research. Some researchers recommended choosing the median $\lambda[18-19,49]$ while others recommended the mean $\lambda$ value [38].

In 2001, there was a research study across 24 states of USA based on 28,301 rainfallrunoff events had determined that the median $\lambda=0.0476$ was the best fit for 252 out of 307 watersheds $[21,48]$. More than $90 \%$ of $\lambda$ were less than 0.2 so $\lambda=0.05$ was the best fit for runoff estimation with the $\lambda$ value ranged from 0 to 0.996 . Furthermore, a research study in WangJiaQiao watershed located at Three Gorges area of China had found out that the median $\lambda=0.048$ was better predicted of runoff than mean $\lambda=0.053$ for 29 sets of large storm events [39]. The $\lambda$ value of WangJiaQiao watershed ranged from 0.010 to 0.154 where $\lambda=0.2$ was far from the range. Moreover, another research study carried out in Loess Plateau, China also determined the $\lambda$ value using median. Based on 757 rainfall events collected from the Zizhou and Xifeng experiment stations, the obtained median $\lambda$ is equal to 0.05 with the range of $\lambda$ between 0.01 and 0.46 [14]. Fu et al (2011) [14] had proved that $\lambda=0.2$ was too high for their study site due to more than $95 \%$ of $\lambda$ value less than 0.2 . Although $\lambda=0.05$ was better fit the observed data when the rainfall amount less than $25 \mathrm{~mm}, \lambda=0.05$ still could not provide accurate runoff estimation. In the other hand, the $C N$ of Loess Plateau of China could not be determined from SCS (1972) [42] due to $\lambda$ value not longer 0.2 as well as there had significant differences in land use and landform. Some research studies used the mean $\lambda$. A research studies carried out on the entire small watershed in Attica, Greece had found that the average $\lambda$ is 0.014 [2] whereas in 186 Australian watersheds, the mean $\lambda$ of 0.05 was proposed by Beck et al. (2009) [3]. Since there is dilemma in choosing $\lambda$ value, the numerical analysis algorithm $[13,21-23,33,38]$ under the guide of inferential statistics $[6,11,26-29,34,50]$ was proposed to apply for $\lambda$ assessment.

Traditionally, the simplified SCS-CN method with $\lambda=0.2$ had been applied and the $C N$ formula as shown in Eq. 3 only applicable when $\lambda=0.2$. The base SCS-CN model, the simplified SCS-CN model and CN formula are stated as below:

$$
\begin{gathered}
Q=\frac{\left(P-I_{a}\right)^{2}}{P-I_{a}+S}, I_{a}=\lambda S \\
Q=\frac{(P-0.2 S)^{2}}{P+0.8 S}
\end{gathered}
$$




$$
C N=\frac{25,400}{S+254}
$$

Where,

$$
\begin{array}{ll}
C N & =\text { Curve Number value } \\
Q & =\text { Runoff depth }(\mathrm{mm}) \\
P & =\text { Rainfall depth }(\mathrm{mm}) \\
I_{a} & =\text { the initial abstraction }(\mathrm{mm}) \\
S & =\text { Maximum potential water retention of a watershed }(\mathrm{mm})
\end{array}
$$

Since most of the researchers had proof that the lambda value was a variable, the simplified SCS-CN method and the $C N$ handbook was not applicable. Based on the research study by Woodward et al (2003) [48] stated that when the $\lambda$ was changed, a different $C N$ must be used. As a result, $S$ correlation of 0.05 and 0.20 was needed to transform the conjugate $C N$ s to equivalent $C N_{0.20}$ [48]. The relationship of $S_{0.05}$ and $S_{0.20}$ was stated below:

$$
S_{0.05}=1.33 S_{0.20}^{1.15}
$$

Eq. 4 only applicable for $\lambda=0.05$ with the rainfall-runoff datasets from 307 watersheds in USA and measured in inches. The runoff equation with $\lambda=0.05$ becomes

$$
\begin{array}{ll}
Q=\frac{(P-0.05 S)^{2}}{P+0.95 S} & P \geq 0.05 S \\
Q=0 & P \leq 0.05 S
\end{array}
$$

$\lambda$ value is not fixed at 0.2 but is a variable in order to improve the runoff prediction. As long as $\lambda \neq 0.2$, the $C N$ cannot determined via tabulated handbook. In this article, there are two issues to be addressed. Firstly, the lambda value of 0.20 was adopted since 1954 without verification. Secondly, the lambda value cannot simply be substituted into SCS-CN model without any $S$ correlation to find $C N$ value.

\section{Methodology}

\subsection{Method}

Since the $\lambda=0.20$ produced inconsistent runoff prediction results, the regional specific $\lambda$ value can be determined through the observed rainfall-runoff behaviour. In order to avoid the dilemma in selecting the mean or median $\lambda$ value, the optimum $\lambda$ and $S$ value were found out by applied non-parametric inferential statistic [25-26, 29] with bootstrapping technique, Bias corrected and accelerated $(\mathrm{BCa})$ procedure of 2000 samples was conducted under $99 \%$ confidence interval range $[9,10,35]$ in order to achieve highest significance at alpha 0.01 level. Since the $\lambda$ value is no longer fixed at $0.20, S$ correlation was used to transform $S_{\lambda}$ back 
to $S_{0.2}[21,48]$. The $S_{0.2}$ was then substituted into $C N$ formula to obtain equivalent $C N_{0.2}$ for the particular watershed.

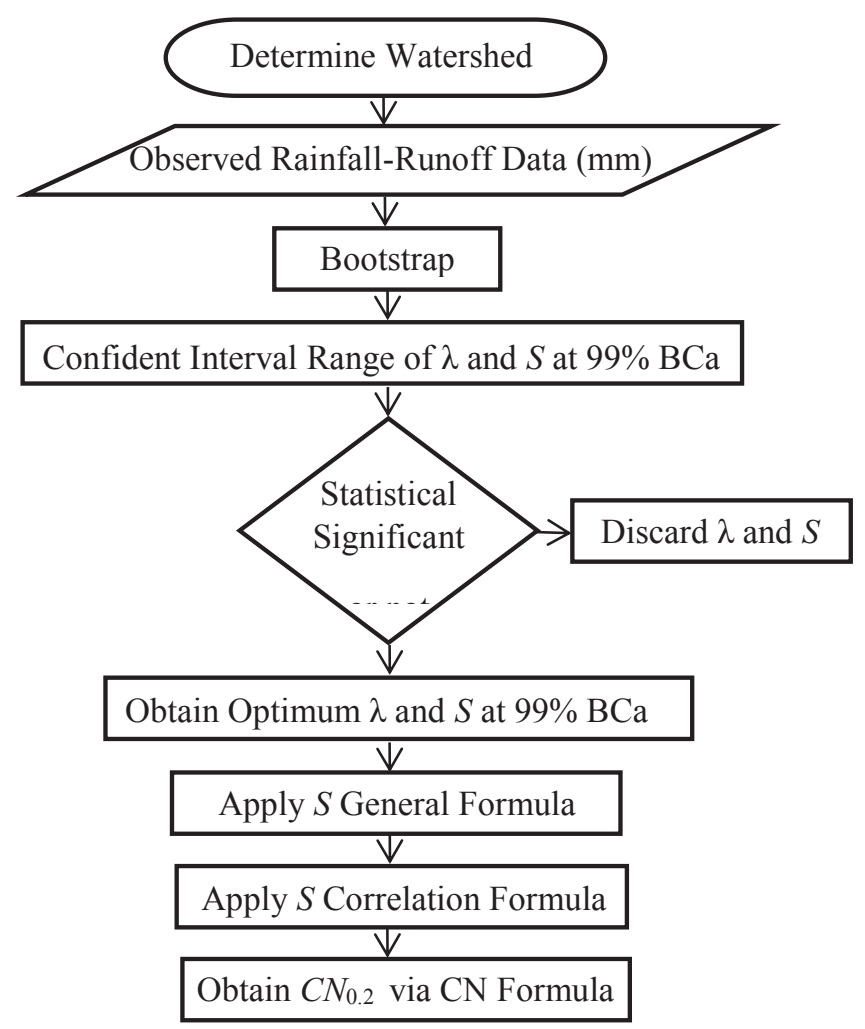

Fig. 1. Flow Chart of Statistics Assessment of $\lambda$ and $S$ Correlation.

\section{Results and discussion}

In 1993, India's handbook had stated that $\lambda=0.1$ for black clay and the rest of soil groups were fixed at $\lambda=0.3$. However, there was no statistical evidence to support these $\lambda$ values for runoff prediction throughout India. In the Engineering Hydrology Textbook Third Edition page 161 Example 5.6 [44], the lambda value was chosen as 0.1 for India watershed due to it is black soil. However, $\lambda=0.1$ for black soil was used without checking its significance. Furthermore, the $C N$ equation in Eq 3 is only applicable when $\lambda=0.2$. Thus, $S$ correlation is needed in order to find the $C N$ for particular watershed [17, 21, 48]. Moreover, Example 5.7 in the Engineering Hydrology Textbook Third Edition at page 161 and 162 [44] direct used the lambda value is equal to 0.3 without further justification and applied in the $C N$ equation without $S$ correlation to obtain the curve number value directly. The $C N$ value obtained in the textbook example without $S$ correlation is actually a Conjugate $C N[17-18,21]$.

Moreover, there were few research studies misused the lambda value without using $S$ correlation when estimate runoff by using SCS-CN method. There was an article studied about the efficiency of $\lambda=0.20$ and $\lambda=0.30$ in estimating the runoff of Tarafeni watershed in India [20]. There were total of 15 sets of observed rainfall-runoff events collected from 1999 
to 2000. [20] stated that $\lambda=0.3$ was applied for all type of soils in India except black soil. On the other hand, Jena et al (2012) [20] concluded that $\mathrm{I}_{\mathrm{a}}=0.20 \mathrm{~S}$ performed better than $\mathrm{I}_{\mathrm{a}}=0.30 \mathrm{~S}$ in Tarafeni watershed. The article concluded that $\lambda=0.3$ was not applicable for the watershed and it could not consistently predict the runoff accurately. Ling (2017) [29] was used skewness and kurtosis to determine the normality of $\lambda$ and $S$. However, there is difficulty to interpret the range of datasets is non-normally distributed. Thus, this article is using ShapiroWilk test to check the normality of datasets. Kolmogorov-Smirnov and Shapiro-Wilk test are the popular normality test that can be generated by using SPSS software. KolmogorovSmirnov test applicable when the sample size more than 2000 whereas Shapiro-Wilk test is used when datasets more than $n \geq 50$ samples and $n \leq 2000$ samples [24]. Table 2 shows the normality tests results of $\lambda$. When the significant value of the Shapiro-Wilk test is greater than 0.05 , the dataset is normally distributed. Based on the significant value of the ShapiroWilk test stated in Table 2 is less than 0.05 , thus the datatset is non-normal distributed [24]. As a results, the derived $\mathrm{BCa} 99 \%$ confident interval range of median $\lambda$ for Tarafeni watershed was $(0.2379,0.4677) . \lambda=0.20$ is not within the $\lambda$ 's confident interval range therefore the value of 0.20 is not statistical significant. Furthermore, the standard deviation of $\lambda$ (Table.1) proved that $\lambda$ cannot be fixed at 0.2 or 0.3 but a variable. As a result, Jena, et al (2012) [20] reached a wrong conclusion to state that $\mathrm{I}_{\mathrm{a}}=0.20 \mathrm{~S}$ performed better than $\mathrm{I}_{\mathrm{a}}=0.30 \mathrm{~S}$. Secondly, in order to achieve high accuracy statistic results by using bootstrap technique, Bias corrected and accelerated $(\mathrm{BCa})$ procedure, the minimum sample size should be at least 20 [21] or 30 [38]. However, the Tarafeni watershed only had 15 sets of rainfall runoff data which is lack of sufficient datasets to produce optimum $\lambda$ value with high accuracy.

Table 1. Bootstrapping BCa $99 \%$ CI results of derived $\lambda$ values at Tarafeni watershed, India.

\begin{tabular}{|c|c|c|c|c|c|c|}
\hline & \multirow{3}{*}{ Statistic } & \multicolumn{4}{|c|}{ Bootstrap $^{a}$} \\
\hline & & & \multirow{2}{*}{ Bias } & \multirow{2}{*}{ Std. Error } & \multicolumn{2}{|c|}{ BCa $99 \%$ Confidence Interval of $\lambda$} \\
\hline & & & & & Lower & Upper \\
\hline \multirow[t]{2}{*}{$\mathrm{N}$} & Valid & 15 & & 0 & & \\
\hline & Missing & 0 & & 0 & & \\
\hline \multicolumn{2}{|c|}{ Mean } & 0.3646 & -0.0019 & 0.0497 & 0.2765 & 0.4939 \\
\hline \multicolumn{2}{|c|}{ Median } & 0.2829 & 0.0119 & 0.0380 & 0.2379 & 0.4677 \\
\hline \multicolumn{2}{|c|}{ Std. Deviation } & 0.2027 & -0.0227 & 0.0694 & 0.0642 & 0.2950 \\
\hline \multicolumn{2}{|c|}{ Variance } & 0.0411 & -0.0039 & 0.0249 & 0.0040 & 0.0877 \\
\hline \multicolumn{2}{|c|}{ Skewness } & 2.4639 & -0.5901 & 0.7432 & 1.1504 & 2.6221 \\
\hline \multicolumn{2}{|c|}{ Kurtosis } & 6.7247 & -2.9349 & 3.6701 & 0.1206 & 7.8417 \\
\hline
\end{tabular}


Table 2. Normality test results of $\lambda$ at Tarafeni watershed, India.

Tests of Normality

\begin{tabular}{|c|c|c|c|c|c|c|}
\hline & \multicolumn{3}{|c|}{ Kolmogorov-Smirnov $^{\mathrm{a}}$} & \multicolumn{3}{|c|}{ Shapiro-Wilk } \\
\hline & Statistic & $\mathrm{df}$ & Sig. & Statistic & $\mathrm{df}$ & Sig. \\
\hline Lambda & 0.246 & 15 & 0.015 & 0.691 & 15 & 0.000 \\
\hline
\end{tabular}

Another research studied at a $15.18 \mathrm{~km}^{2}$ watershed in Greece concluded that the average $\lambda$ was equal to 0.014 . However, there was no statistical check to determine whether the mean $\lambda$ in this research study was the best fit. Based on Table 4 , the $\lambda$ datasets are not normally distributed $(p<0.05)$. As such, the median $\lambda$ should be the better choice than the mean $\lambda$. The derived BCa $99 \%$ confident interval range of median $\lambda$ for Greece watershed was $(0.0053$, 0.0248 ). Although $\lambda=0.014$ is within the confident range, the appropriate optimum $\lambda$ of Greece's watershed should be equal to 0.0082 at alpha $=0.01$ level.

Table 3. Bootstrapping BCa $99 \%$ CI results of derived $\lambda$ values at experimental watershed in Greece.

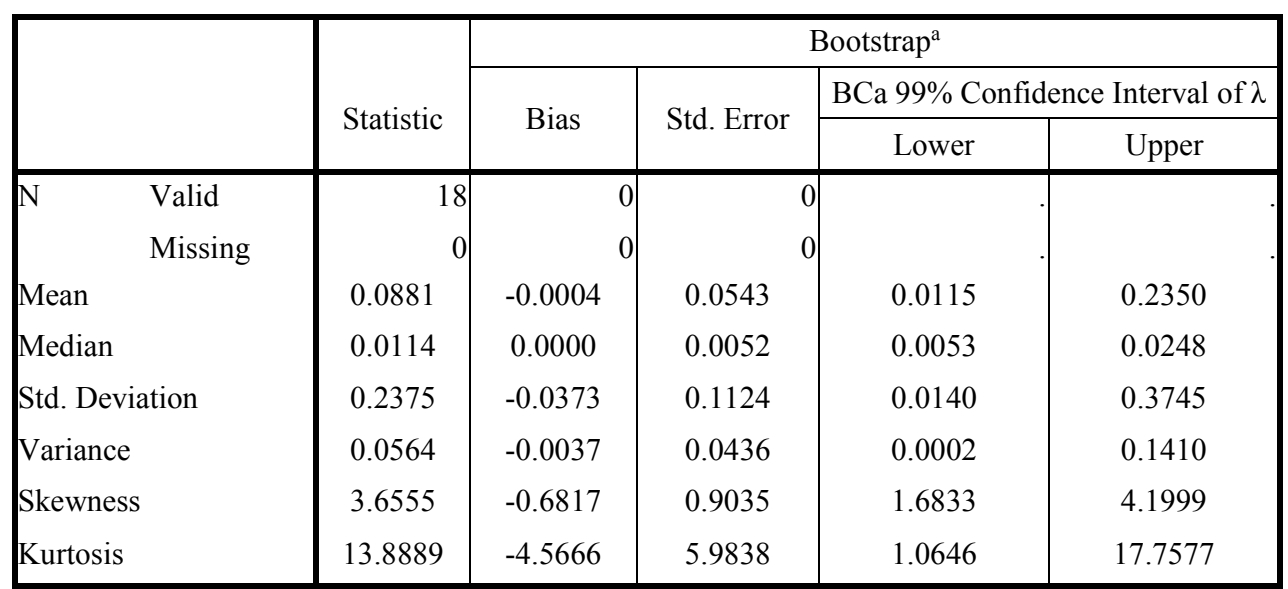

Table 4. Normality test results of $\lambda$ at experimental watershed in Greece.

Tests of Normality

\begin{tabular}{|l|r|r|r|r|r|r|}
\hline & \multicolumn{2}{|c|}{ Kolmogorov-Smirnov $^{\text {a }}$} & \multicolumn{3}{c|}{ Shapiro-Wilk } \\
\cline { 2 - 8 } & Statistic & df & \multicolumn{1}{c|}{ Sig. } & Statistic & df & \multicolumn{1}{c|}{ Sig. } \\
\hline Lambda & 0.432 & 18 & 0.000 & 0.402 & 18 & 0.000 \\
\hline
\end{tabular}

According to the research studied by Jiang (2001) and Woodward et al (2003) [21, 48], the median $\lambda$ value of 0.05 was the best fit for 307 watersheds in USA. The $S$ correlation in their study is stated in Eq. 4. Many research studies adopted median $\lambda$ to calculate the initial abstraction without checking significance and no $S$ correction was derived in their study. For example, the research study of WangJiaQiao watershed located at Three Gorges Area in China adopted $\lambda=0.05$ and the $S$ correlation from USA's research work [21, 48]. However, the 
$S$ correlation showed in Eq. 4 is in inches whereas the 29 sets of observed rainfall-runoff are collected in millimeter. The $S$ correlation is regional specific thus the $S$ correlation determined by Jiang (2001) and Woodward et al (2003) [21, 48] is not suitable for the Chinese watershed. Eq. 7 is the correct $S$ correlation of WangJiaQiao watershed which was derived directly with the $P-Q$ dataset. By using BCa bootstrap under the guide of inferential statistic [25-26], the $S$ correlation of China site can be determined.

$$
S_{0.2}=S_{0.0430}^{0.802}
$$

\section{Conclusion}

As a conclusion, the lambda value in SCS-CN method should not be misused. Simply substitute the insignificant lambda value into SCS-CN model will produce inaccurate surface runoff prediction. By using BCa bootstrap under the guide of inferential statistic [25-26], the lambda value can be verified for its statistical significance at least at alpha $=0.01$ level. While the $\lambda$ value is no longer fixed at 0.2 the $S$ correlation is required to transform $S_{\lambda}$ back to $S_{0.2}$ in order to use the $C N$ equation to calculate the regional $C N$ of a particular watershed. Every region has its own unique collective lambda value thus different regional $S$ correlation is needed to derive the regional specific $C N$ for the particular watershed.

\section{References}

1. M. Ajmal, T.W. Kim, J Irrig Drain Eng, 141, 04014058-1-12 (2015)

2. E.A. Baltas, N.A. Dervos, M.A. Mimikou, HESS, 11, 1825-1829 (2007)

3. H.E. Beck, R.A.M. Jeu, A.I.J.M. Van Dijk, L.A.Bruijnzeel, J-STARS, 2, 250-259 (2009)

4. M, Boszany, J. Irrig Drain E, 115, 139-144 (1989)

5. D.J. Cazier, R.H. Hawkins, Regional application of the curve number method, Water Today and Tomorrow. In: Proceeding of ASCE, Irrigation and Drainage Division Special Conference, 710 (1984)

6. D.R. Cox, Principles of Statistical Inference (2006)

7. F. D’Asaro, G, Grillone, R.H. Hawkins, J.Hydrol.Eng, 19(12), 04014035-1-13 (2014)

8. F. D’Asaro, G, Grillone, J.Hydrol.Eng, 17, 1141-1152 (2012)

9. A.C. Davison, D.V. Hinkley, Bootstrap Methods and Their Application (1997)

10. B. Efron, R. Tibshirani, An Introduction to the Bootstrap (1994)

11. B. Efron, Large-Scale Inference: Empirical Bayes Methods for Estimation, Testing, and Prediction (2010)

12. M. Elhakeem, A. N. Papanicolaou, Water Resour Manag, 23, 2455-2473 (2009)

13. H.O. Fattorini, Infinite Dimensional Optimization and Control Theory (1999)

14. S. Fu, G. Zhang, N. Wang, L. Luo, Transactions of the ASABE, 54, 163-169 (2011)

15. Handbook of Hydrology (1972) Ministry of Agriculture. Govt of India, New Delhi. 
16. R.H. Hawkins, A.V. Khojeini, Initial Abstraction and Loss in the Curve Number Method, Arizona State Hydrological Society Proceedings, 115-119 (2000)

17. R.H. Hawkins, R. Jiang, D.E. Woodward, A.T. Hjelmfelt, J.A. Van Mullem, Continuing Evolution of Rainfall-Runoff and The Curve Number Precedent, $2^{\text {nd }}$ Joint Federal Interagency Conf. Proc. (2010)

18. R.H. Hawkins, T.J. Ward, D.E. Woodward, J.A. Van Mullem, Curve Number Hydrology: State of the Practice (2009)

19. D.C. Howell, Statistical Methods for Psychology (6 $6^{\text {th }}$ Ed.) (2007)

20. S.K. Jena, K.N. Tiwari, A. Pandey, S.K. Mishra, J.Hydrol.Eng, 17, 1278-1286 (2012)

21. R. Jiang, Investigation of Runoff Curve Number Initial Abstraction Ratio, MS Thesis (2001)

22. L. Jon, A First Course in Combinatorial Optimization (2004)

23. N. Jorge, J.W. Stephen, Numerical Optimization (2006)

24. Laerd Statistics. Testing for Normality using SPSS Statistics (n.d.)

25. L. Ling, Z. Yusop, Inferential Statistics of Claim assessment. Proceedings of the $3^{\text {rd }}$ International Conference on Quantitative Sciences and Its Applications (2014)

26. L. Ling, Z. Yusop, Inferential Statistics Modelling and Claim re-assessment. ICCEMS Conference Proceedings (2014b)

27. L. Ling, Z. Yusop, The Calibration of a Rainfall-Runoff Model. International Conference on Advances in Civil and Environmental Engineering (2015)

28. L. Ling, Z. Yusop, ARPN JEAS, 11, 9706-9711 (2016)

29. L, Ling. Deriving the Initial Abstraction Ratio Coefficient for Runoff Prediction in Peninsula Malaysia. PhD thesis (2017)

30. S. Mishra, V. Singh, Hydrol Process, 18, 1291-1313 (2004)

31. A. Mordecai, Nonlinear Programming: Analysis and Methods (2003)

32. V.V.D. Narayana, Soil and Water Conservation Research in India, Indian Council of Agricultural Research (1993)

33. V.M. Ponce, R.H. Hawkins, J.Hydrol.Eng, 1, 11-19 (1996)

34. C.R. Rao, Statistics and Truth: Putting Chance to Work (1997)

35. J.A.J. Rochoxicz, eJSiE, 4, 1-23 (2011)

36. A. Ruszczyński, Nonlinear Optimization, (2006)

37. K.S. Ramasastry, S.M. Seth, Rainfall-Runoff Relationships. Rep. RN-20, National Institute of Hydrology (1985)

38. L, Schneider, R.H. McCuen, J. Irrig. Drain. Eng.,131, 282-290 (2005)

39. Z.H. Shi, L.D. Chen, N.F. Fang, D.F. Qin, C.F. Cai, Catena, 77, 1-7 (2009) 
40. P.K. Singh, S.K. Mishra, R. Berndtsson, M.K. Jain, R.P. Pandey, Water Resour Manag., 29, 4111-4127 (2015)

41. Soil Conservation Service (SCS), National Engineering Handbook, Sec. 4 Hydrology. (1964)

42. Soil Conservation Service (SCS), National Engineering Handbook, Sec. 4 Hydrology. (1972)

43. E.P. Springer, B.J. McGurk, R.H. Hawkins, G.B. Goltharp, Curve Numbers from Watershed Data, In: Proceeding of Irrigation and Drainage Symposium on Watershed Management, 938-950 (1980)

44. K. Subramanya, Engineering Hydrology Third Edition (2008)

45. United States Department of Agriculture - Natural Resource Conservation Service (USDA-NRCS), Part-630 Hydrology, National Engineering Handbook. In: Chap 10, Estimation of Direct Runoff from Storm Rainfall (2004)

46. D.R. Vandersypen, J.S. Bali, Y.P. Yadav, Handbook of Hydrology Central Unit (Soil Cons) India. Ministry of Agriculture, New Delhi (1972)

47. X. Wang, T. Liu, W. Yang, HSJ, 57, 1118-1140 (2012)

48. D.E. Woodward, R.H. Hawkins, R. Jiang, A.T. Hjelmfelt, J.A. Van Mullem, Q.D. Quan, Runoff Curve Number Method: Examination of the Initial Abstraction Ratio, World Water \& Environmental Resources Congress, 1-10 (2003)

49. D.B. Wright, Understanding Statistics: An Introduction for the Social Sciences (1997)

50. G.A. Young, R.L. Smith, Essentials of Statistical Inference (2005)

51. Y. Yuan, W. Nie, S.C. McCutcheon, E.V. Taguas, Hydrol Process, 28, 774-783 (2014)

52. S.M. Zhou, D. Warrington, W.T. Lei, Q.X. Lei, M.L. Zhang, J. Hydrol. Eng., 20, 04014095-1-9 (2015) 